\title{
Rural-Urban Disparity in Oral Health-Related Quality of Life
}

Gaber $\mathrm{A}^{1,2}$, Galarneau $\mathrm{Ch}^{3}$, Feine $\mathrm{Js}^{1,2}$, Emami $\mathrm{E}^{2,3}$.

${ }^{1}$ Faculty of Dentistry, McGill University, 2001 McGill College Ave., Montréal, QC, H3A 1G1, Canada

${ }^{2}$ Faculty of Dentistry, Université de Montréal, Pavillon Roger-Gaudry, 2900 boul. Eduard Montpetit, Montréal, QC H3T 1J4, Canada

${ }^{3}$ School of Public Health, Public Health Research Institute, CRCHUM, Université de Montréal

\author{
* Corresponding author \\ Elham Emami, DDS, MSc, PhD \\ Professor, Faculty of Dentistry \\ School of Public Health, Public Health Research Institute, CRCHUM, Université de Montréal \\ Adjunct Professor, Faculty of Dentistry, McGill University \\ Pavillon Roger-Gaudry, local C-219, Université de Montréal \\ C.P. 6128, succ. Centre-ville, Montreal, Quebec, H3C 3J7, Canada \\ Tel.: +1 (514) 343-6053 \\ elham.emami@umontreal.ca
}




\section{ABSTRACT}

Objectives: The objective of this population-based cross-sectional study was to estimate ruralurban disparity in the oral health-related quality of life of the Quebec adult population.

Methods: A two-stage sampling design was used to collect data from the 1,788 parents/caregivers of schoolchildren living in the 8 regions of the province of Quebec in Canada. Andersen's behavioural model for health services utilization was used as a conceptual framework. Place of residency was defined according to the Statistics Canada Census Metropolitan Area and Census Agglomeration Influenced Zone classification. The outcome of interest was oral health-related quality of life measured using the OHIP-14 validated questionnaire. Data weighting was applied, and the prevalence, extent and severity of negative oral health impacts were calculated. Statistical analyses included descriptive statistics, bivariate analyses and binary logistic regression.

Results: The prevalence of poor oral health-related quality life (OHRQoL) was statistically higher in rural areas than in urban zones $(P=0.02)$. Rural residents reported a significantly higher prevalence of negative daily-life impacts in pain, psychological discomfort and social disability OHIP domains $(P<0.05)$. Additionally, the rural population showed a greater number of negative oral health impacts $(P=0.03)$. There was no significant rural-urban difference in the severity of poor oral health. Logistic regression indicated that the prevalence of poor OHRQoL was significantly related to place of residency $(\mathrm{OR}=1.6 ; 95 \% \mathrm{CI}=1.1-2.5 ; P=0.022)$, perceived oral health ( $\mathrm{OR}=9.4 ; 95 \% \mathrm{CI}=5.7-15.5 ; P<0.001)$, dental treatment needs factors (perceived need for dental treatment, pain, dental care seeking) $(\mathrm{OR}=8.7 ; 95 \% \mathrm{CI}=4.8-15.6 ; P<0.001)$ and education $(\mathrm{OR}=2.7 ; 95 \% \mathrm{CI}=1.8-3.9 ; P<0.001)$.

Conclusion: The results of this study suggest a potential difference in OHRQoL of Quebec rural and urban populations, and a need to develop strategies to promote oral health outcomes, specifically for rural residents. Further studies are needed to confirm these results. 


\section{INTRODUCTION}

Since Hippocrates introduced the concept of the effect of place on health ${ }^{1}$, research in various disciplines has been conducted to examine whether contextual and cultural characteristics of where people live, rather than compositional differences in individuals, can explain disparity in health outcomes ${ }^{1-4}$. In addition, various conceptual frameworks have been used to better understand the predictors of this disparity ${ }^{2,4-8}$. Andersen's behavioural model of health services utilization has been widely accepted as a predictive and explanatory model to evaluate the role of place in determining health and oral health outcomes ${ }^{9}$. According to this model, oral health outcome is a function of predisposing factors, enabling resources, and the need for dental care 9 , ${ }^{10}$. It has been shown that contextual characteristics of geographical place can play a significant role in rural-urban general and oral health inequality 5,11, 12. The urban environment might mitigate the potential negative influence of rural environmental characteristics such as geographic remoteness, socioeconomic deprivation and inadequate access to oral health-care services and contribute to better oral health or oral health-related quality of life (OHRQoL) ${ }^{13-19}$. Research findings from different nations worldwide have shown that people living in rural areas are less satisfied with their oral health and have higher rates of untreated dental caries, periodontal disease and tooth loss ${ }^{20-26}$. Moreover, rural residents are less likely to engage in disease prevention and promotion of healthy behaviours, because there are fewer health information resources and inadequate health care provider counseling ${ }^{27,}{ }^{28}$. According to the Canadian Community Health Survey (2001), rural residents had a lower rate of use of dental services than their urban counterparts ${ }^{29}$. Utilization of health care services is an important determinant of oral health but is far from equal, geographically. This disparity can be explained mainly by unequal distribution of health professionals, as well as inequitable and inadequate access to oral health care services in rural and remote zones ${ }^{20,30,31}$. In 2009-2010, about 90.3\% of the dental workforce in the province of Quebec were located in urban areas, and only $0.3 \%$ of the total dental workforce maintained their practice in remote rural zones ${ }^{32}$. These variations may directly affect oral health, both in terms of morbidity and in perceived oral health.

Emami et al. ${ }^{33}$ conducted a qualitative study in a rural region of Quebec (2014) to explore how rural residents perceive their oral health and access to dental care. Their results showed that, although rural residents didn't perceive rurality as a threat to their oral health, they were 
concerned about their limited access to dental care. In fact, geographic distance and lack of public transportation were reported as major barriers to oral health, especially for people with physical disabilities.

However, investigation of the rural-urban disparity in oral health status and its determinants has been neglected in some parts of North America, including in Canada. Epidemiological research in oral health-related quality of life is important, as its focus is not limited to physical health, but extends beyond that to capture the impact of oral health status on functional, social and psychological wellbeing ${ }^{34}$. Furthermore, the resultant information will help policy makers to develop effective models for provision of oral health care where it is needed.

To our knowledge, this is the first population-based study that aims to provide empirical data on rural-urban oral health-related quality of life and its determinants in Canada. We tested the hypothesis that there is no rural-urban difference in the prevalence, extent and severity of negative oral health impacts.

\section{METHODS}

1. Design, setting, participants

The data for this study were drawn from a mixed-methods sequential exploratory project on Quebec's rural oral health (Rural Oral Health Study). The qualitative phase of this study was published previously ${ }^{33}$. The quantitative phase consisted of a cross-sectional population-based study conducted in 2012-2013. To facilitate the logistics and to reduce the costs, this study was conducted with the collaboration of Institut National de Santé Publique du Québec (INSPQ) and in parallel with the INSPQ/Quebec Ministry of Health and Social Services (MSSS) provincial clinical study on the oral health of second (7-8 years of age) and sixth grade (11-12) schoolchildren. The target population for this study was the parents/caregivers of schoolchildren residing in the 8 regions of Quebec province whose administrative dental officers agreed to collaborate in the data collection. Ethical approval was provided by the institutional review board of the Université de Montréal, and participants signed consent forms before enrolment.

A random subsample of Quebec's MSSS provincial survey schoolchildren was selected using stratified two-stage sampling. Oversampling of certain schools in some rural regions was 
conducted to increase the reliability and precision of estimates for these regions. The sampling design took into account the proper weighting of each unit of this sample and the unequal probabilities of such a sample, in order to be representative of the rural-urban population of parents/caregivers of schoolchildren (second- and sixth-grade population).

The parents/legal caregivers were invited to participate in this sub-study by the dental examiner or the hygienist responsible for the INSPQ study, via their children. A total of 1,906 individuals agreed to participate in the study and returned the completed questionnaire with a participation rate of 37\%; however, after pairing with the clinical INSPQ data, the final sample used for data analysis was reduced to 1,788 . This was based on the predefined sampling and statistical analysis plan.

2. Data collection: Main outcome and independent variables

This report presents the results of the primary outcome of the study: oral health-related quality of life. Andersen's behavioral model of health services utilization was used as the study's conceptual model ${ }^{9}$ with an increased focus of the effect of place of residence. Rurality was defined according to the 2006 Metropolitan Area and Census Agglomeration Influenced Zone (MIZ) provided by Statistics Canada ${ }^{35}$. According to the 2011 Canadian Census, about $19 \%$ of all Quebecers live in rural areas ${ }^{36}$. The residential postcode was used to assign respondents' census geography using the Postal Code Conversion File Plus (PCCF4F+) ${ }^{37}$.

The Oral Health Impact Profile (OHIP-14) was used to measure oral health-related quality of life $^{38}$. This validated and highly reliable $(\alpha=0.88)$ oral health disease-specific instrument has been widely used in dental care service use surveys ${ }^{13}, 39$; it has been tested and validated in English-speaking and French-speaking Canadians for cross-cultural validity ${ }^{40}$. The OHIP-14 consists of two items for each of the seven dimensions: functional limitation, physical pain, psychological discomfort, physical disability, psychological disability, social disability and handicap ${ }^{38}$. The items are rated on 5-point Likert scales ("never" $=0$, "rarely" $=1$, “occasionally"=2, "often" $=3$, “always"=4). The OHIP-14 total range is $0-56$ points, with lower scores indicating better oral health-related quality of life.

Table 3 presents the independent variables used in the data analysis. These variables consisted of indicators of predisposing factors, enabling resources, oral health needs and utilization of dental services and were collected by means of a self-administered questionnaire. The items of this 
questionnaire were taken from the Canadian Oral Health Measures Survey and Quebec oral health surveillance questionnaires ${ }^{41-44}$.

The predisposing factors included age, gender, ethnicity, occupation, education, oral health behaviors and oral health knowledge. While these risk factors originate in individuals, many of them may become reinforced within social contexts, such as rural environment. The behavioural risk factors for parent's perceived oral health were defined as 'smoking', and infrequent flossing and tooth brushing as detailed in Table 3. Parental oral health knowledge was measured by two questions: "Have you ever received information on how to prevent dental decay for your child?" and "agreement with the sentence below: 'I do not have sufficient information to know exactly what to do to prevent dental decay for my child'." Perceived general health was assessed by the question "How would you rate your overall health?" while perceived oral health was measured by the question "How would you rate the health of your mouth?"

Enabling resources included the equivalent household income, dental insurance coverage, distance to dental care, mode of transportation to dental care facilities, type of dental care providers and availability of dental care provider. Perceived need was assessed by three questions in regard to persistent pain during the last year, perceived need for dental treatment, and time away from work or daily activities seeking dental treatment during the preceding year. Finally, the use of dental services was assessed through questions about dental visits during the previous year and the reason(s) behind the visit(s).

\section{Statistical analyses}

The standard sampling weights were used to adjust the estimates on the basis of distribution within the regions, and to take into account any disproportionality of the sample and the differential probability of selection and non-response. Furthermore, the $P$-values of Chi-square tests were adjusted to take into account the survey design effect with a value of 1.5. The design effect is the extent to which the expected sampling error departs from the sampling error that can be expected under random sampling 45,46 . Data imputation for the outcome variable was not essential because only $0.5 \%$ of the participants missed two questions or more. The calculation of OHIP scores for these participants was based on the remaining items. In order to obtain frequency counts, percentages and univariate means and to test for normality, the data were first 
subjected to descriptive statistical tests. For analysis of OHIP-14 data, three summary variables were defined according to Slade et al. ${ }^{47}$ :

- Prevalence: the percentage of people who answered one or more items with 'fairly often' or 'very often'.

- Extent: the number of items reported as 'fairly often' or 'very often'.

- Severity: the sum of ordinal answers of all 14 items with a range from 0 to 56.

The student t-test (for continuous variables) and Chi-square test (for categorical variables) were used to compare rural-urban populations in the prevalence, extent and severity of perceived poor oral health, the seven dimensions of the OHIP-14, as well as for all Andersen model-based variables (predisposing factors, enabling resources, dental needs). Individual items of the OHIP were dichotomized for analysis to "low negative impacts" if the impact occurred "rarely, never or sometimes" versus "high negative impacts" if the impact occurred "often or always." The student t-test and Chi-square test were used to compare dichotomized OHIP items across the studied independent variables.

The equivalent household income was calculated by dividing the median of each income category by the square root of the number of persons in the household ${ }^{48,49}$. The oral health knowledge and dental treatment needs variables were considered as composite variables developed from combining the items mentioned earlier, and were coded as ' 1 ' or ' 0 '. The variable was considered ' 1 ' if any of the questions were answered yes. This approach was applied to overcome any possible underestimation of positive responses for any of the composite questions ${ }^{50}$.

Unadjusted odds ratios and their $95 \%$ confidence intervals were calculated to determine the strength of the association between the independent variables and the OHIP prevalence (Table 3). The collinearity between independent variables was verified using Spearman's correlation to avoid unduly inflated variance of any estimated regression coefficients. No collinearity between variables was detected.

Binary logistic regression was used to measure the effect of place of residency on prevalence of poor OHRQoL (dependent variable) while adjusting for the other variables in the conceptual model. Two models were constructed; the first model included variables from predisposing, 
enabling and needs factors (Table 4). The second included only the predisposing and needs factors (Table 5). Independent variables with results from univariate analyses $P \leq 0.05$ (Table 3 ) were incorporated into the model. Variables in the final model were selected using a backward stepwise procedure; the decision to remove terms was based on a likelihood-ratio test. By using this approach, all potential predictors were first included in the "full" model, then predictors were sequentially removed if their removal did not result in a significant change in the loglikelihood. The statistical significance was set at $P \leq 0.05$, and goodness-of-fit was assessed using Hosmer-Lemeshow test. Nagelkerke $\mathrm{R}^{2}$ was used to examine how useful the explanatory variables are in predicting the dependant variable. The analyses were performed using statistical package SPSS version 22 (IBM Corp., Armonk, NY, USA). Post-hoc power calculations were performed using the PASS 12 statistical programme. The sample size of 1,788 was sufficient to detect a difference of $5 \%$ in prevalence of poor OHRQoL between rural and urban populations, with $80 \%$ power.

\section{RESULTS}

The study sample consists of 333 (18.6\%) individuals living in rural areas and 1,455 (81.4\%) living in urban zones. The mean age of the sample population was $39.3 \pm 5.2$ years and ranges from 21 to 91 years (Table 1). From a total of 1,788 parents, the majority of respondents were married/partnered females with level of education higher than secondary school. The majority had full-time employment, and about $40 \%$ had an equivalent annual income of less than $\$ 40,000$. Compared to residents in urban areas, rural residents had a lower education level, employment rate and income $(P<0.001)$.

In terms of dental service utilization, there was no statistically significant difference between rural $(82.3 \%)$ and urban $(86.3 \% ; P=0.124)$ residents; however, compared to urbanites, rural residents were more likely not to have seen a dentist for routine checkups $(P=0.03)$. Dental insurance coverage of rural residents was about half that of their urban counterparts $(P<0.001)$.

The distance travelled to access a dental clinic was approximately 1.5 times greater for rural residents $(P<0.001)$ and, compared to their urban counterparts, rural residents used mostly their own car (versus public transportation or walking; $P=0.004$; Table 2). 
The internal consistency estimate of reliability of the OHIP-14 scores was excellent (Cronbach's alpha coefficient $=0.9$ ).

In the total sample, the prevalence of negative oral health impacts reported by the sample population was $9.2 \%$, and the extent of impacts was $0.2 \pm 0.3$. The severity of the impacts (mean $=$ OHIP-14 total score) was $4.0 \pm 0.9$.

There was a significant rural-urban difference in the percentage of individuals with negative oral health impacts $(P=0.02)$. Compared to urban residents, rural residents reported a significantly greater prevalence of negative oral health impacts in the pain, psychological discomfort and social disability OHIP domains $(P<0.05$; Figure 2$)$. The rural residents experienced a significantly greater extent of negative impact $(P=0.03)$, as well. However, the difference in severity scores between rural and urban dwellers was not significant (Figure 1).

The Andersen-based model variables and their association with the prevalence of poor OHRQoL is shown in Table 3. There was a statistically significant association between the prevalence of poor OHRQoL and predisposing variables (place of birth, language, marital status, education, occupation, smoking, perceived general health, perceived oral health), as well as enabling resources (income, dental insurance coverage, type of clinic, difficulty to find a dentist, having a family dentist) and the reason to use dental services.

The logistic regression analysis of the prevalence of poor oral health-related quality of life (Table 4) by predisposing, enabling and needs factors revealed that the odds of having poor oral healthrelated quality of life were significantly greater in individuals with dental treatment needs $(\mathrm{OR}=8.5 ; 95 \% \mathrm{CI}=4.7-15.3 ; P<0.001)$, poor perceived oral health $(\mathrm{OR}=6.6 ; 95 \% \mathrm{CI}=3.9-11.2$; $P<0.001)$, not having access to private dental clinics ( $\mathrm{OR}=3.8 ; 95 \% \mathrm{CI}=2.1-6.9 ; P<0.001)$, lower income $(\mathrm{OR}=2.7 ; 95 \% \mathrm{CI}=1.7-4.2 ; P<0.001)$ and lower level of education $(\mathrm{OR}=2.1 ; 95 \%$ $\mathrm{CI}=1.4-3.1 ; P<0.001)$. Living in rural zones increased the odds of poor oral health-related quality of life but was marginally significant $(\mathrm{OR}=1.6 ; 95 \% \mathrm{CI}=1.0-2.5 ; P=0.050)$.

When only predisposing and needs factors were entered in the model, along with place of residency (Table 5), living in rural areas increased the odds of poor oral health-related quality of life (OR=1.6; $95 \% \mathrm{CI}=1.1-2.5 ; P=0.022$; Nagelkerke $\mathrm{R}^{2}=0.3$ ) by $60 \%$. The odds of having poor OHRQoL were 9 times more in individuals with perceived poor oral health $(\mathrm{OR}=9.4 ; 95 \%$ 
$\mathrm{CI}=5.7-15.5 ; P<0.001)$ and 8 times more in individuals with dental treatment needs $(\mathrm{OR}=8.7$; 95\% CI=4.8-15.6; $P<0.001)$. Moreover, people with secondary school education level or less had about 3 times higher chance of having poor OHRQoL $(\mathrm{OR}=2.7 ; 95 \% \mathrm{CI}=1.8-3.9 ; P<0.001)$ than those with higher education.

\section{DISCUSSION}

This study examined rural-urban disparity in oral health-related quality of life in the context of social determinants of health care. To the best of our knowledge, this is the first study that examine the rural-urban differences in oral health-related quality of life in Canada.

Different theoretical frameworks have been introduced to conceptualize how place characteristics influence health attributes. Some of these frameworks follow a biomedical perspective and are based on the spatial diffusion of physical and biological risk factors ${ }^{5}$. Some conceptual frameworks put emphasis on social capital, social engagement, place-related resilience and sense of belonging to explain the role of place in health outcomes ${ }^{6,7}$. These sociocultural attributes have the potential to tie people and communities together and positively influence health outcomes ${ }^{51,52}$. Others frameworks focus on social determinants of health and the link between place and macro-social factors ${ }^{2,4,8}$. In the present study, Andersen's behavioral model ${ }^{9}$ was used as the conceptual model. This model has been widely used in health care services research, including oral health care services ${ }^{53,54}$. Although Andersen's model didn't allow this study to capture all factors related to rural/urban disparity in oral health-related quality of life, it allowed us to take into account the important elements including predisposing factors, enabling resources, the need for care and use of dental services. It is noteworthy that all existing models have certain limitations and none of them can capture the whole complete picture of health and its broad range of determinants. Anderson's Model may be limited to explore the determinants of health rather than identification of interaction between them or recognising required actions and entry points for policy makers' interventions.

The results of this study are in line with the literature, in that along with income and education, perceived oral health and need of dental care are associated with poor OHRQoL 55 -60 38, 61-62. Furthermore, an important finding of this study is that type of dental care services can be a predictor of oral health-related quality of life. 
Our results revealed that the Canadian population, in general, has good oral health-related quality of life in comparison with populations from other countries, such as the United Kingdom, Spain and Australia 19, 47 . This variation may be due to differences in study participant characteristics. For example, the majority of participants in this study were young educated females. According to a systematic review conducted by Carneiro et al. ${ }^{63}$, women tend to be more dissatisfied and to report greater negative impacts in OHRQoL than men do. Another factor that could influence OHRQoL is difference in ethnicity 63, 64. Various studies showed that shared norms and behaviours which are unique for each culture could influence one's rating of oral health ${ }^{65,66}$.

Our findings show that the prevalence and the extent of poor oral health-related quality of life in the rural population are significantly higher than for their urban counterparts, even after adjusting for predisposing factors such as socio-economic variables and dental treatment needs. These results support the literature that, in general, rurality is associated with poor oral health outcomes. Several studies from Australia, the United States and some developing countries showed rural-urban difference in the rate of oral diseases such as caries, periodontal disease and tooth loss $20-26$.

Although research on the impact of rurality on oral health-related quality of life is not extensive, the available results are comparable with our findings within the Quebec population. A cohort study conducted in Brazil revealed that OHIP scores were higher in single individuals, women and rural dwellers ${ }^{14}$. Findings from a recent survey in India ${ }^{16}$ showed that OHIP-14 scores were significantly associated with age, gender, poorer clinical outcomes and place of residency. Rural dwellers reported poorer oral health-related quality of life than urban dwellers ${ }^{16}$. These findings were similar to those from a study conducted in a Greek population ${ }^{18}$. Analysis of data from a 2003 National Health Survey of Chilean adults indicated that gender, rurality and poor selfreported general quality of life were associated with poor oral health-related quality of life ${ }^{15}$. In a study on an edentulous Croatian population, the predictors of oral health-related quality of life were age, education and type of oral rehabilitation, as well as the place of residency ${ }^{17}$. Another study conducted in Spain assessed the determinants of oral health-related quality of life, revealing that participants older than 45 years living in rural areas, with lower level of socioeconomic status and poor hygiene, had poorer oral health-related quality of life ${ }^{19}$. 
Furthermore, our results are also comparable to previous studies ${ }^{16}, 18$, showing that rural residents had lower OHIP scores in three dimensions: Physical pain, Psychological discomfort and Social disability.

In this study, we built two regression models based on Andersen's behavioural model ${ }^{9}$. When adjusting for predisposing, enabling and need factors, the place of residence was marginally associated with the outcome. However, when enabling resources were removed from the model, the association between place of residency and oral health-related quality of life became statistically significant. This suggests that rurality may aggregate barriers to oral health-related quality of life, such as a low level of insurance coverage, lack of public transportation and the need to travel further for dental care. In terms of predisposing factors, residing in a rural setting appears to aggravate poor health-related behaviours, such as smoking, that could adversely impact oral health status and oral health-related quality of life ${ }^{5,67-69}$. Our findings showed that the rate of smoking was significantly higher in rural than in urban populations. Lack of regular dental visits can be explained by lack of knowledge about the importance of oral health ${ }^{54}$. However, oral health education and motivation by oral health professionals can be affected by scarce and inefficiently allocated oral health resources in rural regions ${ }^{32,33}$. On the other hand, it has been shown that optimum access to oral health resources is an important factor for better oral health-related quality of life ${ }^{58}$. According to our study, rural residents were twice as far from dental care services compared to their urban counterparts, and they were also less motivated to seek regular dental check-ups. These factors collectively may play a role in the deterioration of their oral health-related quality of life.

According to the literature, endurance and resiliency characteristics of the rural population increase its willingness to adapt to the surrounding environment in such a way as to make them resist care seeking ${ }^{70}$. This can be considered as a risk factor, since this type of adaptation could promote the adoption of poor health-related behaviours, discourage care seeking and, consequently, influence oral health status ${ }^{71}$. Indeed, because expectations drive ratings of quality of life, the rural lifestyle and self-sufficient mind-sets can explain why no significant differences in severity of oral health-related quality of life were detected between the studied populations.

Despite rural-urban variations in enabling resources to access dental care, our results show no difference between both populations in the percentage of people who reported visiting dentists in 
the previous year or in the frequency of these visits. These findings contradict what was reported by the Canadian Community Health Survey $2.1^{29,72}$, in which elderly Canadians residing in rural settings had fewer dental visits than the urban residents. It is worth mentioning that greater utilization of services for urgent care does not necessarily have a similar positive influence on OHRQoL, as has been shown for routine preventive dental visits. This was shown in an Australian study in which frequency and time since the last dental visit were not associated with OHIP-14 severity ${ }^{58}$.

Some limitations should be taken into account when interpreting the results of the present study. Firstly, the study was an add-on to the Institut National de Santé Publique du Québec (INSPQ) provincial clinical study and the data were independently gathered via the vehicle of this provincial survey which was supported by the Ministry of Health and Social Services. Therefore, the study didn't aim to investigate the effect of the primary unit of analysis (schools) on the perceived oral health of schoolchildren's parents/caregivers. Furthermore, the study participants were limited to the parents/caregivers of schoolchildren in the second (7-8 years of age) and sixth grade (11-12), as well as not including clinical indicators such as caries and tooth loss. This narrow variability in certain variables limited the study's capacity to analyze all the factors that may be associated with the study outcome. For example, the majority of our study participants were young females, who represent the main caregivers. This limitation didn't allow us to analyze a potential gender difference in rural/urban OHRQoL disparity. Finally, the participation rate was quite low. However, we used various strategies to compensate for these limitations. These include the use of a design-based model ${ }^{73}$ and weighting the data to adjust the estimates on the basis of distribution within the regions. The data weighting process was produced by the INSPQ to ensure that the sample is representative of the population of the eight rural/urban areas targeted. This strategy took into account the initial weights of the students for the national/regional component of the 2012-2013 classification of statistical sectors, the participation rate in the different deprivation strata, the geographical areas and the language of instruction within the large regions. Finally, margining was performed on these weights, ensuring the representativeness of the number of pupils according to the classification of statistical sectors, the grade level and the gender. 


\section{CONCLUSION}

Within the limitations of this study, the results showed that there is a rural-urban difference in oral health-related quality of life in the adult Quebec population. These results suggest that there is a need to develop strategies to promote oral health at the population level, specifically for rural residents. This indicates that the collaboration of government, health policy makers and oral health care professionals is needed to implement public dental services, educational interventions and other needs-based strategies tailored for disadvantaged populations.

\section{ACKNOWLEDGMENTS}

The authors gratefully acknowledge the Institut National de Santé Publique du Québec (INSPQ), the Ministry of Health and Social Services (MSSS) and their regional dentists in charge of collecting the data for this survey. We also would like to express our gratitude to Mr. Denis Hamel, Mr Miguel Chagnon, Dr. David Rothwell and Mr. Pierre Rompre for their advice regarding data handling and analysis. This study was funded by The Quebec-Network for Oral Health Research and Dr. Emami CIHR - Clinician Scientist Award- Phase II entitled Investigating Urban-Rural Disparities in Oral Health and Oral Health Services: A Quebec Profile. 


\section{REFERENCES}

1. Macintyre S, Ellaway A. Neighborhoods and Health: An Overview. In: Kawachi I, Berkman LF, editors. Neighborhoods and Health. New York, NY: Oxford University Press; 2003. p. 20-42.

2. Bernard P, Charafeddine R, Frohlich KL, Daniel M, Kestens Y, Potvin L. Health inequalities and place: a theoretical conception of neighbourhood. Soc Sci Med. 2007;65(9):1839-52.

3. De Koninck M, Pampalon R. Living environments and health at the local level: The case of three localities in the Québec City region. Can J Public Health. 2007; 98 Suppl 1:S45-53.

4. Macintyre S, Ellaway A, Cummins S. Place effects on health: how can we conceptualise, operationalise and measure them? Soc Sci Med. 2002;55(1):125-39.

5. Curtis S, Rees Jones I. Is there a place for geography in the analysis of health inequality? Sociol Health Illn. 1998;20(5):645-72.

6. Bourdieu P. The forms of capital(1986). In: Szeman I, Kaposy T, editors. Cultural theory: An anthology. UK: Wiley Blackwell; 2011. p. :81-93.

7. Carpiano RM. Neighborhood social capital and adult health: an empirical test of a Bourdieu-based model. Health Place. 2007;13(3):639-55.

8. Verheij RA. Explaining urban-rural variations in health: a review of interactions between individual and environment. Soc Sci Med. 1996;42(6):923-35.

9. Andersen RM. Revisiting the behavioral model and access to medical care: does it matter? J Health Soc Behav. 1995;36(1):1-10.

10. Andersen RM. National health surveys and the behavioral model of health services use. Med Care. 2008;46(7):647-53.

11. Pampalon R, Hamel D, Gamache P. Health inequalities in urban and rural Canada: comparing inequalities in survival according to an individual and area-based deprivation index. Health Place. 2010;16(2):416-20.

12. Ricketts TC, SHEPS CG. Geography and disparity in health. Washington, DC: National Academy Press; 2002.

13. Williams S, Parker E, Jamieson L. Oral health-related quality of life among ruraldwelling Indigenous Australians. Aust Dent J. 2010;55(2):170-6. 
14. Teixeira MFN, Martins AB, Celeste RK, Hugo FN, Hilgert JB. Association between resilience and quality of life related to oral health in the elderly. Rev Bras Epidemiol. 2015;18(1):220-33.

15. Espinoza I, Thomson WM, Gamonal J, Arteaga O. Disparities in aspects of oral healthrelated quality of life among Chilean adults. Community Dent Oral Epidemiol. 2013;41(3):24250.

16. Sanadhya S, Aapaliya P, Jain S, Sharma N, Choudhary G, Dobaria N. Assessment and comparison of clinical dental status and its impact on oral health-related quality of life among rural and urban adults of Udaipur, India: A cross-sectional study. J Basic Clin Pharm. 2015;6(2):50.

17. Kranjčić J, Mikuš A, Peršić S, Vojvodić D. Factors Affecting Oral Health-Related Quality of Life Among Elderly Croatian Patients. Acta Stomatol Croat. 2014;48(3):174-82.

18. Papaioannou W, Oulis C, Latsou D, Yfantopoulos J. Oral health related quality of life of Greek adolescents: a cross-sectional study. Eur Arch Paediatr Dent. 2011;12(3):146-50.

19. Montero J, Yarte J-M, Bravo M, López-Valverde A. Oral health-related quality of life of a consecutive sample of Spanish dental patients. Med Oral Patol Oral Cir Bucal. 2011;16(6):e810-e5.

20. Skillman SM, Doescher MP, Mouradian WE, Brunson DK. The challenge to delivering oral health services in rural America. J Public Health Dent. 2010;70(s1):S49-S57.

21. Fos P, Hutchison L. The state of rural oral health: A Literature Review. In: Gamm L, Hutchison L, Dabney B, Dorsey A, ed. by. Rural healthy People 2010: A companion document to Healthy people 2010, volume 2. Texas: The Texas A\&M University System Health Science Center, School of Rural Public Health, Southwest Rural Health Research Center; 2017. p. 199203.

22. Vargas CM, Dye BA, Hayes K. Oral health care utilization by US rural residents, National Health Interview Survey 1999. J Public Health Dent. 2003;63(3):150-7.

23. Vargas CM, Yellowitz JA, Hayes KL. Oral health status of older rural adults in the United States. J Am Dent Assoc. 2003;134(4):479-86.

24. Ahn S, Burdine JN, Smith ML, Ory MG, Phillips CD. Residential rurality and oral health disparities: influences of contextual and individual factors. J Prim Prev. 2011;32(1):29-41. 
25. Crocombe LA, Bell E, Barnett T. Is it time for an advanced rural dentist? Aust J Rural Health. 2014;22(2):86.

26. Ha D, Amarasena N, Crocombe L. The dental health of Australia's children by remoteness. Canberra, Australia: Australian Government, 2009.

27. Nagarajan KV. Rural and remote community health care in Canada: beyond the Kirby Panel Report, the Romanow Report and the federal budget of 2003. Can J Rural Med. 2004;9(4):245-51.

28. Canadian Population Health Initiative. Kachimaa Mawiin-Maybe for Sure: Finding a Place for Place in Health Research and Policy. Ottawa: Canadian Institute for Health Information, 2005.

29. Martinez J. Does living in rural communities rather than cities really make a difference in people's health and wellness? Montréal: Institut national de santé publique du Québec, Direction planification, recherche et innovation, Unité connaissance-surveilance; 2004.

30. Ogunbodede E, Kida I, Madjapa H, Amedari M, Ehizele A, Mutave R, et al. Oral Health Inequalities between Rural and Urban Populations of the African and Middle East Region. Adv Dent Res. 2015;27(1):18-25.

31. Naito M, Yuasa H, Nomura Y, Nakayama T, Hamajima N, Hanada N. Oral health status and health-related quality of life: a systematic review. J Oral Sci. 2006;48(1):1-7.

32. Emami E. Mapping Quebec Dental Workforce: Ranking Rural Oral Health Disparities. IADR 2011.

33. Emami E, Wootton J, Galarneau C, Bedos C. Oral health and access to dental care: a qualitative exploration in rural Quebec. Can J Rural Med. 2014;19(2):63-70.

34. Sheiham A. Oral health, general health and quality of life. Bull World Health Organ. 2005;83(9):644-.

35. Statistics Canada. Census metropolitan influenced zones: Detailed definition Ottawa: Statistics Canada; 2012 [updated 2015 May 13 cited 2015 August 22]. Available from: http://www.statcan.gc.ca/pub/92-195-x/2011001/other-autre/miz-zim/def-eng.htm.

36. Statistics Canada. Population, urban and rural, by province and territory (Quebec) 2011. Available from: http://www.statcan.gc.ca/tables-tableaux/sum-som/101/cst01/demo62f-eng.htm.

37. Wilkins R. PCCF+ Version 4F User's Guide. Ottawa: Health Analysis and Measurement Group, 2005. 
38. Slade GD, Spencer AJ. Development and evaluation of the oral health impact profile. Community Dent Health. 1994;11(1):3-11.

39. Slade GD. Derivation and validation of a short-form oral health impact profile. Community Dent Oral Epidemiol. 1997;25(4):284-90.

40. Allison P, Locker D, Jokovic A, Slade G. A cross-cultural study of oral health values. J Dent Res. 1999;78(2):643-9.

41. Brodeur JM, Payette M, Benigeri M, Olivier M, Chabot D, Williamson S, et al. Étude sur la santé bucco-dentaire des adultes de 18 ans et plus du Québec. Résultats du sondage. Montreal: Direction de la santé publique de Montréal-Centre, 1995.

42. Brodeur J.M., Payette M., Olivier M., Chabot D., Benigeri M., Williamson S. Étude 1994-1995 sur la santé buccodentaire des adultes québécois de 35 à 44 ans. Québec: Ministère de la Santé et des Services sociaux; 1998. Report No.: 8.

43. Benigeri M, Brodeur JM, Olivier M, Bedos C. Knowledge and perceptions of adolescents regarding oral health. Can J Public Health. 2002;93(1):54-8.

44. Oral Health Status Data Collection. Oral Health and the Canadian Health Measures Survey (CHMS). [Internet]. Health Canada. [cited 15/2/2012]. Available from: http://www.hcsc.gc.ca/ahc-asc/branch-dirgen/fnihb-dgspni/ocdo-bdc/project-eng.php.

45. Henry GT. Practical sampling. Newbury Park, Calif: Sage;1990.

46. Levy PS, Lemeshow S. Sampling of populations: methods and applications: John Wiley \& Sons; 2013.

47. Slade G, Nuttall N, Sanders A, Steele J, Allen P, Lahti S. Impacts of oral disorders in the United Kingdom and Australia. Br Dent J. 2005;198(8):489-93.

48. Statistics Canada. Low Income Lines, 2011-2012 2013. Available from: http://www.statcan.gc.ca/pub/75f0002m/75f0002m2013002-eng.pdf.

49. Celeste RK, Bastos JL. Mid-point for open-ended income category and the effect of equivalence scales on the income-health relationship. Rev Saude Publica. 2013;47 Suppl 3:16871.

50. European Commission, Organisation for Economic Co-operation and Development. Handbook on Constructing Composite Indicators. Paris: OECD; 2008.

51. Kitchen P, Williams A, Chowhan J. Sense of community belonging and health in Canada: A regional analysis. Social Indicators Research. 2012;107(1):103-26. 
52. Carpiano RM. Toward a neighborhood resource-based theory of social capital for health: Can Bourdieu and sociology help? Soc Sci Med. 2006;62(1):165-75.

53. Baker S. Applying Andersen's behavioural model to oral health: what are the contextual factors shaping perceived oral health outcomes? Community Dent Oral Epidemiol. 2009;37(6):485-94.

54. Andersen R, Davidson P. Ethnicity, aging, and oral health outcomes: a conceptual framework. Adv Dent Res. 1997;11(2):203-9.

55. Locker D. Disparities in oral health-related quality of life in a population of Canadian children. Community Dent Oral Epidemiol. 2007;35(5):348-56.

56. Pistorius J, Horn JG, Pistorius A, Kraft J. Oral health-related quality of life in patients with removable dentures. Schweiz Monatsschr Zahnmed. 2013;123(11):964-71; 55.

57. Tsakos G, Sheiham A, Iliffe S, Kharicha K, Harari D, Swift CG, et al. The impact of educational level on oral health-related quality of life in older people in London. Eur J Oral Sci. 2009;117(3):286-92.

58. Crocombe L, Mahoney G, Spencer A, Waller M. Will improving access to dental care improve oral health-related quality of life? Aust Dent J. 2013;58(2):192-9.

59. Tubert-Jeannin S, Riordan PJ, Morel-Papernot A, Porcheray S, Saby-Collet S. Validation of an oral health quality of life index (GOHAI) in France. Community Dent Oral Epidemiol. 2003;31(4):275-84.

60. Locker D, Gibson B. Discrepancies between self-ratings of and satisfaction with oral health in two older adult populations. Community Dent Oral Epidemiol. 2005;33(4):280-8.

61. Allen PF. Assessment of oral health related quality of life. Health Qual Life outcomes. 2003;1(1):40.

62. Sheiham A, Maizels J, Cushing A. The concept of need in dental care. Int Dent J. 1982;32(3):265-70.

63. Cohen-Carneiro F, Souza-Santos R, Rebelo MAB. Quality of life related to oral health: contribution from social factors. Cien Saude Colet. 2011;16:1007-15.

64. Newton J, Khan F, Bhavnani V, Pitt J, Gelbier S, Gibbons D. Self-assessed oral health status of ethnic minority residents of South London. Community Dent Oral Epidemiol. 2000;28(6):424-34. 
65. Hilton IV, Stephen S, Barker JC, Weintraub JA. Cultural factors and children's oral health care: a qualitative study of carers of young children. Community Dent Oral Epidemiol. 2007;35(6):429-38.

66. Idler EL, Benyamini Y. Self-rated health and mortality: a review of twenty-seven community studies. J Health Soc Behav. 1997:21-37.

67. Isman. Oral health. In: Loue S, Quill BE, editors. Handbook of rural health. New York: Springer Science \& Business Media; 2001.

68. Eberhardt MS, Pamuk ER. The importance of place of residence: examining health in rural and nonrural areas. Am J Public Health. 2004;94(10):1682-6.

69. Crooks VA, Andrews GJ. Primary Health Care : People, Practice, Place. England: Ashgate: Farnham 2009.

70. Martins AB, Dos Santos CM, Hilgert JB, De Marchi RJ, Hugo FN, Pereira Padilha DM. Resilience and Self-Perceived Oral Health: A Hierarchical Approach. J Am Geriatr Soc. 2011;59(4):725-31.

71. Dixon J, Welch N. Researching the rural-metropolitan health differential using the 'social determinants of health'. Aust J Rural Health. 2000;8(5):254-60.

72. McDonald JT, Conde H. Does geography matter? The health service use and unmet health care needs of older Canadians. Can J Aging. 2010;29(01):23-37.

73. Masood M, Newton T, Reidpath D. Comparison of four analytic strategies for complex survey data: a case-study of Spanish data. Epidemiology, Biostatistics and Public Health. 2016;13(1). 


\section{LIST OF TABLES:}

Table 1 Socio-demographic characteristics of study participants $(\mathrm{n}=1788)$

Table 2 Rural/urban disparity according to Anderson model-based variables (predisposing factors, enabling resources, dental treatment needs, dental service utilization) 23

Table 3 Percentage of people reporting poor oral health-related quality of life according to Anderson model-based variables 26

Table 4 Oral health-related quality of life and place of residency: Logistic regression model (predisposing factors, enabling resources, needs).

Table 5 Oral health-related quality of life and place of residency: Logistic regression model (predisposing factors, needs)

\section{LIST OF FIGURES:}

Figure 1 Rural/urban disparity in oral health-related quality of life

Figure 2 Rural/urban disparity in OHIP-14 dimensions 
Table 1 Socio-demographic characteristics of study participants $(\mathrm{n}=1788)$

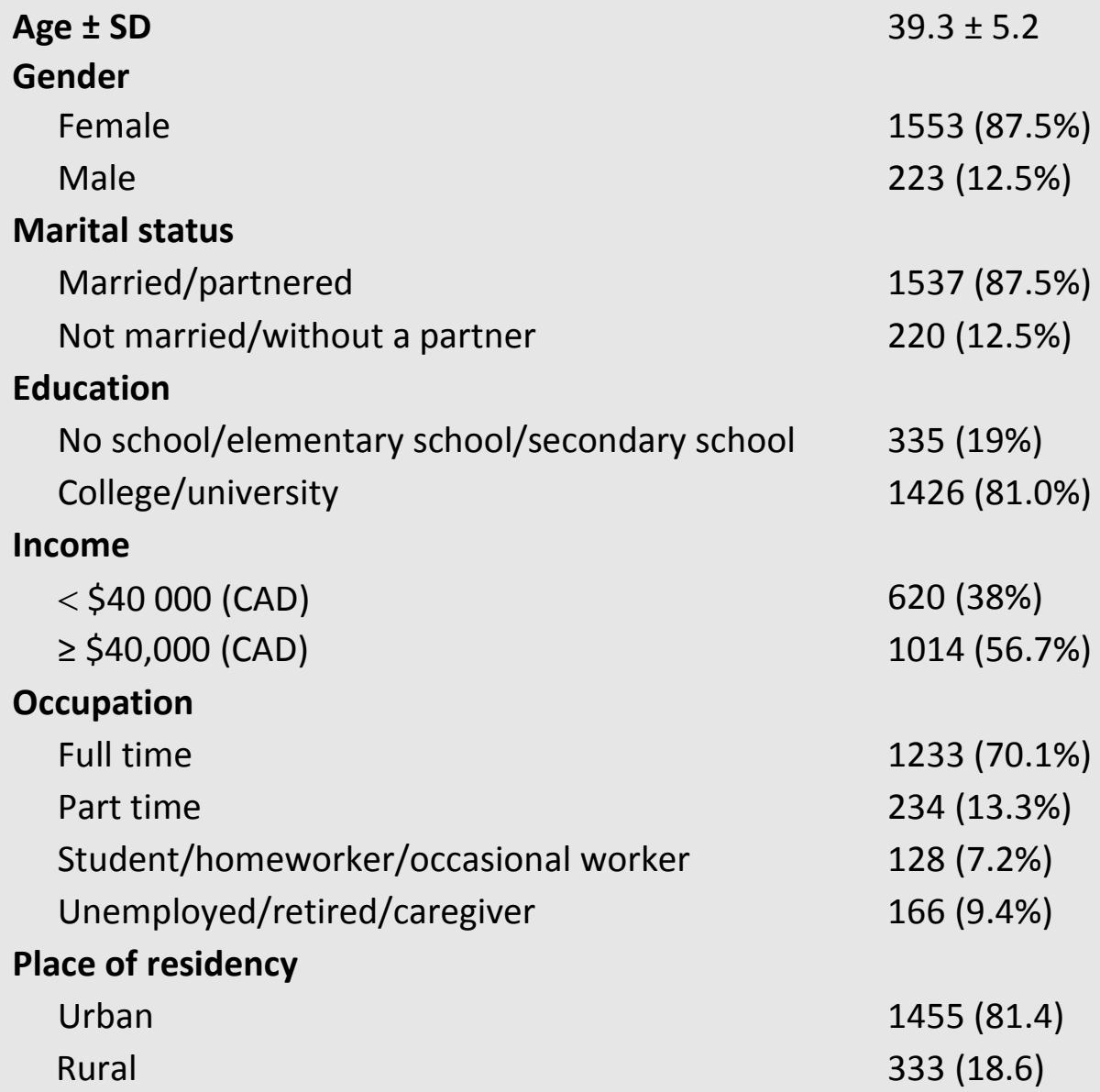


Table 2 Rural/urban disparity according to Anderson model-based variables (predisposing factors, enabling resources, dental treatment needs, dental service utilization)

\begin{tabular}{|c|c|c|c|}
\hline & Urban & Rural & P-value* \\
\hline \multicolumn{4}{|l|}{ Predisposing factors } \\
\hline \multicolumn{4}{|l|}{ Age } \\
\hline Years (mean) & $39.6 \pm 5.2$ & $38.2 \pm 5.05$ & 0.481 \\
\hline \multicolumn{4}{|l|}{ Gender } \\
\hline Male & $191(13.2 \%)$ & $32(9.7 \%)$ & 0.150 \\
\hline Female & $1253(86.8 \%)$ & 299 (90.3\%) & \\
\hline \multicolumn{4}{|l|}{ Place of birth } \\
\hline Canada & 1341 (92.4\%) & $320(96.4 \%)$ & 0.032 \\
\hline Elsewhere & $111(7.6 \%)$ & $12(3.6 \%)$ & \\
\hline \multicolumn{4}{|l|}{ Ethnicity } \\
\hline North American & 959 (87.9\%) & 232 (95.9\%) & 0.001 \\
\hline European & $49(4.5 \%)$ & $7(2.9 \%)$ & \\
\hline $\begin{array}{l}\text { Africa/South American/Middle } \\
\text { Eastern }\end{array}$ & $40(3.7 \%)$ & $1(0.4 \%)$ & \\
\hline \multicolumn{4}{|l|}{ Language } \\
\hline French & $1290(88.7 \%)$ & 311 (93.7\%) & $<0.001$ \\
\hline English & $87(6.0 \%)$ & $20(6.0 \%)$ & \\
\hline Other & $78(5.4 \%)$ & $1(0.3 \%)$ & \\
\hline \multicolumn{4}{|l|}{ Marital status } \\
\hline With a partner & 1261 (88.1\%) & 276 (84.9\%) & 0.208 \\
\hline Without a partner & 171 (11.9\%) & 49 (15.1\%) & \\
\hline \multicolumn{4}{|l|}{ Education } \\
\hline Secondary school or less & $232(16.2 \%)$ & $104(31.9 \%)$ & $<0.001$ \\
\hline University/college & $1204(83.8 \%)$ & $222(68.1 \%)$ & \\
\hline \multicolumn{4}{|l|}{ Occupation } \\
\hline Full time & $1040(72.5 \%)$ & 194 (59.5\%) & $<0.001$ \\
\hline Part time & $183(12.8 \%)$ & $51(15.6 \%)$ & \\
\hline $\begin{array}{l}\text { Student/homeworker/occasional } \\
\text { worker }\end{array}$ & $82(5.7 \%)$ & 45 (13.8\%) & \\
\hline Unemployed/retired/caregiver & $129(9 \%)$ & $36(11 \%)$ & \\
\hline
\end{tabular}




\begin{tabular}{|c|c|c|c|}
\hline & Urban & Rural & $p$-value* \\
\hline \multicolumn{4}{|l|}{ Smoking } \\
\hline Smoker & $107(7.4 \%)$ & $43(13.1 \%)$ & 0.005 \\
\hline Not smoker & $1346(92.6)$ & $285(86.9)$ & \\
\hline \multicolumn{4}{|l|}{ Tooth brushing } \\
\hline One time per day or more & $1432(98.4 \%)$ & $329(99.1)$ & 0.447 \\
\hline Less than one time per day & $23(1.6 \%)$ & $3(0.9)$ & \\
\hline \multicolumn{4}{|l|}{ Tooth flossing } \\
\hline One time per day or more & $401(30.7 \%)$ & 95 (31\%) & 0.920 \\
\hline Less than one time per day & 906 (69.3\%) & $211(69 \%)$ & \\
\hline \multicolumn{4}{|l|}{ Perceived general health } \\
\hline Good & $1411(98.0 \%)$ & $323(98.5 \%)$ & 0.634 \\
\hline Poor & $29(2.0 \%)$ & $5(1.5 \%)$ & \\
\hline \multicolumn{4}{|l|}{ Perceived oral health } \\
\hline Good & $1386(95.4 \%)$ & $314(94.6 \%)$ & 0.609 \\
\hline Poor & $67(4.6 \%)$ & $18(5.4 \%)$ & \\
\hline \multicolumn{4}{|l|}{ Perceived oral health knowledge } \\
\hline I have oral health knowledge & $1405(97.4 \%)$ & $311(94.8 \%)$ & 0.049 \\
\hline I do not have oral health knowledge & $38(2.6 \%)$ & $17(5.2 \%)$ & \\
\hline
\end{tabular}

\section{Enabling resources}

Equalized income

$$
\begin{aligned}
& \geq \$ 40,000 \text { (CAD) } \\
& <\$ 40,000 \text { (CAD) }
\end{aligned}
$$

$\begin{array}{lll}890(61.1 \%) & 125(37.5 \%) & <0.001 \\ 435(29.9 \%) & 185(55.6 \%) & \\ & & \\ 403(27.7 \%) & 174(52.4 \%) & <0.001 \\ 1041(71.5 \%) & 157(47.3 \%) & \end{array}$

Distance to dental clinic

$$
\begin{aligned}
& \text { No } \\
& \text { Yes } \\
& \text { Mean (km) }
\end{aligned}
$$

Type of clinic

Private dental clinic

Denturist's clinic**

Other

Difficulty to find a dentist

$$
\begin{aligned}
& \text { Difficult } \\
& \text { Easy }
\end{aligned}
$$

Having a family dentist

$$
\text { Yes }
$$

No

Transportation

Public

transportation/carpooling/walking

Owned car

\section{1}

21.6

$<0.001$

$1383(95.5 \%)$

$33(2.3 \%)$

$32(2.2 \%)$

$313(94.3 \%)$

0.038

$15(4.5 \%)$

$4(1.5 \%)$

$$
85 \text { (5.9) }
$$

1362 (94.1)

25 (7.6)

0.344

305 (92.4)

1371 (94.8)

75 (5.2)

317 (95.2)

0.890

16 (4.8)

146 (10. 1\%)

$13(4.0 \%)$

0.004

$1302(89.9 \%) \quad 315(96.0 \%)$ 


\begin{tabular}{|c|c|c|c|}
\hline & Urban & Rural & $p$-value* \\
\hline \multicolumn{4}{|l|}{ Dental treatment needs } \\
\hline \multicolumn{4}{|l|}{ Need for dental treatment } \\
\hline Yes & $784(53.9 \%)$ & $171(51.5 \%)$ & 0.522 \\
\hline No & $671(46.1 \%)$ & $161(48.5 \%)$ & \\
\hline \multicolumn{4}{|l|}{ Dental service utilization } \\
\hline \multicolumn{4}{|l|}{ Dentist visit during the last year } \\
\hline Yes & $1248(86.3 \%)$ & $274(82.3 \%)$ & 0.124 \\
\hline No & $59(17.7)$ & $198(13.7)$ & \\
\hline \multicolumn{4}{|l|}{ Reason for visit during the last year } \\
\hline Check-up & 749 (51.9\%) & $145(43.8 \%)$ & 0.029 \\
\hline Treatment or emergency & $694(48.1 \%)$ & $186(56.2 \%)$ & \\
\hline \multicolumn{4}{|c|}{$\begin{array}{l}\text { Student t-test and Chi square test. } \\
* * \text { A Denturist is a dental health care professional who provides denture care directly to the public. }\end{array}$} \\
\hline
\end{tabular}


Table 3 Percentage of people reporting poor oral health-related quality of life according to Anderson model-based variables

Never/rarely/ Often/always

sometimes impacts P-value *

impacts

\begin{tabular}{|c|c|c|c|}
\hline \multicolumn{4}{|l|}{ Predisposing factors } \\
\hline \multicolumn{4}{|l|}{ Age } \\
\hline Years (mean) & $39.3 \pm 5.1$ & $38.8 \pm 5.8$ & 0.226 \\
\hline \multicolumn{4}{|l|}{ Gender } \\
\hline Male & $200(12.4 \%)$ & $23(14.0 \%)$ & \multirow[t]{2}{*}{0.635} \\
\hline Female & 1407 (87.6\%) & $141(86.0 \%)$ & \\
\hline \multicolumn{4}{|l|}{ Place of birth } \\
\hline Canada & 1518 (93.9\%) & 142 (87.1\%) & \multirow[t]{2}{*}{0.006} \\
\hline Elsewhere & $98(6.1 \%)$ & $21(12.9 \%)$ & \\
\hline \multicolumn{4}{|l|}{ Ethnicity } \\
\hline North American & $1074(66.3 \%)$ & 117 (71.3\%) & \multirow[t]{2}{*}{0.289} \\
\hline Other nationalities & $545(33.7 \%)$ & $47(28.7 \%)$ & \\
\hline \multicolumn{4}{|l|}{ Language } \\
\hline French & 1481 (91.5\%) & $120(72.7 \%)$ & \multirow[t]{3}{*}{$<0.001$} \\
\hline English & $82(5.1 \%)$ & $25(15.2 \%)$ & \\
\hline Other & $56(3.5 \%)$ & $20(12.1 \%)$ & \\
\hline \multicolumn{4}{|l|}{ Marital status } \\
\hline Married/with a partner & 1401 (88.1\%) & 131 (80.9\%) & \multirow[t]{2}{*}{0.030} \\
\hline Single/divorced/widowed & $189(11.9 \%)$ & $33(19.1 \%)$ & \\
\hline \multicolumn{4}{|l|}{ Education } \\
\hline$\leq$ Secondary school & $267(16.7 \%)$ & $68(42 \%)$ & \multirow[t]{2}{*}{$<0.001$} \\
\hline College/university & $1329(83.3 \%)$ & $94(58 \%)$ & \\
\hline \multicolumn{4}{|l|}{ Occupation } \\
\hline Full time & $1146(71.8 \%)$ & $86(54.1 \%)$ & \multirow[t]{4}{*}{$<0.001$} \\
\hline Part time & $216(13.5 \%)$ & $18(11.3)$ & \\
\hline $\begin{array}{l}\text { Student/homeworker/occasional } \\
\text { worker }\end{array}$ & $101(6.3 \%)$ & $26(16.4 \%)$ & \\
\hline Unemployed/retired/caregiver & $133(8.3 \%)$ & $29(18.2 \%)$ & \\
\hline \multicolumn{4}{|l|}{ Smoking } \\
\hline No & 1495 (92.7\%) & 131 (79.9\%) & \multirow[t]{2}{*}{$<0.001$} \\
\hline Yes & $117(7.3 \%)$ & $33(20.1 \%)$ & \\
\hline
\end{tabular}




\begin{tabular}{|c|c|c|c|}
\hline & $\begin{array}{l}\text { Never/rarely/ } \\
\text { sometimes } \\
\text { impacts }\end{array}$ & $\begin{array}{l}\text { Often/always } \\
\text { impacts }\end{array}$ & $P$-value * \\
\hline \multicolumn{4}{|l|}{ Tooth brushing } \\
\hline One time per day or more & $1595(98.6 \%)$ & $161(98.2 \%)$ & 0.771 \\
\hline Less than one time per day & $23(1.4 \%)$ & $3(1.8 \%)$ & \\
\hline \multicolumn{4}{|l|}{ Tooth flossing } \\
\hline One time per day or more & 451 (30.9\%) & $42(28.2 \%)$ & 0.577 \\
\hline Less than one time per day & 1009 (69.1\%) & $107(71.8 \%)$ & \\
\hline \multicolumn{4}{|l|}{ Perceived general health } \\
\hline Good & $1580(98.7 \%)$ & $150(91.5 \%)$ & $<0.001$ \\
\hline Poor & $21(1.3 \%)$ & $14(8.5 \%)$ & \\
\hline \multicolumn{4}{|l|}{ Perceived oral health } \\
\hline Good & $1580(97.7 \%)$ & $116(70.7 \%)$ & $<0.001$ \\
\hline Poor & $37(2.3 \%)$ & $48(29.3 \%)$ & \\
\hline \multicolumn{4}{|l|}{ Perceived oral health knowledge } \\
\hline I have oral health knowledge & $1556(96.9 \%)$ & 156 (96.9\%) & 0.979 \\
\hline $\begin{array}{l}\text { I do not have oral health } \\
\text { knowledge }\end{array}$ & 49 (3.1\%) & $5(3.1 \%)$ & \\
\hline \multicolumn{4}{|l|}{ Enabling resources } \\
\hline \multicolumn{4}{|l|}{ Income } \\
\hline$\geq \$ 40,000$ (CAD) & $971(60 \%)$ & $42(25.6 \%)$ & $<0.001$ \\
\hline$<\$ 40,000(C A D)$ & $514(31.7 \%)$ & $106(64.6 \%)$ & \\
\hline \multicolumn{4}{|l|}{ Dental Insurance coverage } \\
\hline Yes & 1097 (67.7\%) & $96(58.9 \%)$ & 0.027 \\
\hline No & $510(31.5 \%)$ & $67(41.1 \%)$ & \\
\hline \multicolumn{4}{|l|}{ Distance to dental clinic } \\
\hline Mean (km) & 14.2 & 11.6 & 0.173 \\
\hline \multicolumn{4}{|l|}{ Type of clinic } \\
\hline Private dentist clinic & 1557 (96.6\%) & $135(82.3 \%)$ & $<0.001$ \\
\hline Denturist's clinic** & $33(2.0 \%)$ & $15(9.1 \%)$ & \\
\hline $\begin{array}{l}\text { Hospitals/dental schools or } \\
\text { university/other locations }\end{array}$ & $21(1.3 \%)$ & $14(8.5 \%)$ & \\
\hline \multicolumn{4}{|l|}{ Difficulty to find a dentist } \\
\hline Difficult & $91(5.7 \%)$ & $19(11.7 \%)$ & 0.013 \\
\hline Easy & $1519(94.3 \%)$ & $144(88.3 \%)$ & \\
\hline
\end{tabular}




\begin{tabular}{|c|c|c|c|}
\hline & $\begin{array}{l}\text { Never/rarely/ } \\
\text { sometimes } \\
\text { impacts }\end{array}$ & $\begin{array}{l}\text { Often/always } \\
\text { impacts }\end{array}$ & $P$-value * \\
\hline \multicolumn{4}{|l|}{ Having a family dentist } \\
\hline Yes & 1544 (96\%) & 139 (84.8\%) & $<0.001$ \\
\hline No & $65(4 \%)$ & $25(15.2 \%)$ & \\
\hline \multicolumn{4}{|l|}{ Transportation } \\
\hline My car & 1472 (91.5\%) & $141(86.5 \%)$ & 0.083 \\
\hline $\begin{array}{l}\text { Public transportation } \\
\text { /carpooling/walking }\end{array}$ & $137(8.5 \%)$ & $22(13.5 \%)$ & \\
\hline \multicolumn{4}{|l|}{ Degree of rurality } \\
\hline Strong MIZ & 76 (4.7\%) & $16(9.8 \%)$ & 0.433 \\
\hline Moderate MIZ & $172(10.6 \%)$ & $24(14.6 \%)$ & \\
\hline Weak and null MIZ & $41(2.5 \%)$ & $4(2.4 \%)$ & \\
\hline \multicolumn{4}{|l|}{ Dental treatment needs } \\
\hline \multicolumn{4}{|l|}{ Need for dental treatment } \\
\hline No need & 815 (50.3\%) & $13(7.9 \%)$ & $<0.001$ \\
\hline Yes & $804(49.7 \%)$ & $151(92.1 \%)$ & \\
\hline \multicolumn{4}{|l|}{ Dental service utilization } \\
\hline \multicolumn{4}{|l|}{ Dental visit in the past year } \\
\hline Yes & $1385(86.1 \%)$ & $132(80.5 \%)$ & 0.113 \\
\hline No & 224 (13.9\%) & $32(19.5 \%)$ & \\
\hline \multicolumn{4}{|l|}{ Reason for visit } \\
\hline Check-up & 852 (53.1\%) & $38(23.2 \%)$ & $<0.001$ \\
\hline Treatment or emergency & 753 (46.9\%) & $126(76.8 \%)$ & \\
\hline $\begin{array}{l}\text { *P-value adjusted for the effect plan. } \\
\text { Student } t \text {-test and Chi square test. } \\
{ }^{* *} \text { A Denturist is a dental health care } \\
\text { public. }\end{array}$ & who provic & denture car & tly to the \\
\hline
\end{tabular}


Table 4 Oral health-related quality of life and place of residency: Logistic regression model (predisposing factors, enabling resources, needs)

\begin{tabular}{|c|c|c|c|c|}
\hline Category & Reference category & $\begin{array}{c}\text { Unadjusted OR } \\
(95 \% \mathrm{Cl})\end{array}$ & $\begin{array}{c}\text { Adjusted OR } \\
(95 \% \mathrm{Cl}) \\
\end{array}$ & $\boldsymbol{P}$-value \\
\hline \multicolumn{5}{|l|}{ Dental treatment needs } \\
\hline Yes & No & $11.5(6.5,20.2)$ & $8.5(4.7,15.3)$ & $<0.001$ \\
\hline \multicolumn{5}{|l|}{ Perceived oral health } \\
\hline Poor & Good & $17.4(10.9,27.7)$ & $6.6(3.9-11.2)$ & $<0.001$ \\
\hline \multicolumn{5}{|l|}{ Type of dental clinic } \\
\hline $\begin{array}{l}\text { Denturist* and public } \\
\text { clinics }\end{array}$ & Private dentist clinic & $6.2(3.8,9.9)$ & $3.8(2.1,6.9)$ & $<0.001$ \\
\hline \multicolumn{5}{|l|}{ Equivalent income } \\
\hline$<\$ 40,000(C A D)$ & $\geq 40000 \$(C A D)$ & $4.8(3.3,6.9)$ & $2.7(1.7,4.2)$ & $<0.001$ \\
\hline \multicolumn{5}{|l|}{ Education } \\
\hline $\begin{array}{l}\text { No school/elementary } \\
\text { school/secondary school } \\
\text { Place of residency }\end{array}$ & College or university & $3.6(2.6,5.1)$ & $2.1(1.4,3.1)$ & 0.001 \\
\hline Rural & Urban & $1.7(1.2,2.5)$ & $1.6(1.0,2.5)$ & 0.050 \\
\hline
\end{tabular}


Table 5 Oral health-related quality of life and place of residency: Logistic regression model (predisposing factors, needs)

\begin{tabular}{lllll}
\hline Category & Reference category & $\begin{array}{c}\text { Unadjusted OR } \\
(\mathbf{9 5 \%} \mathrm{Cl})\end{array}$ & $\begin{array}{c}\text { Adjusted OR } \\
(\mathbf{9 5 \%} \mathrm{Cl})\end{array}$ & P-value \\
\hline $\begin{array}{l}\text { Perceived oral health } \\
\quad \text { Poor }\end{array}$ & Good & $17.4(10.9,27.7)$ & $9.4(5.7-15.5)$ & $<0.001$ \\
$\begin{array}{c}\text { Dental treatment needs } \\
\text { Yes } \\
\begin{array}{l}\text { Education } \\
\text { No school/elementary } \\
\text { school/secondary school }\end{array}\end{array}$ & Non & $11.5(6.5,20.2)$ & $8.7(4.8,15.6)$ & $<0.001$ \\
$\begin{array}{l}\text { Place of residency } \\
\text { Rural }\end{array}$ & Urban & $3.6(2.6,5.1)$ & $2.7(1.8,3.9)$ & $<0.001$ \\
\hline
\end{tabular}

Non-significant factors excluded from the final model: marital status, smoking and perceived general health 